\title{
Jordanian Consumer's Evaluation of Retail Store Attributes: The Influence of Consumer Religiosity
}

\author{
Dr. Hamza Salim Khraim (Corresponding author) \\ Chair of Marketing Department, Middle East University, PO box 383, Amman 11610, Jordan \\ E-mail: hkhraim@meu.edu.jo \\ Dr. Aymen Salim Khraim \\ Marketing Department, Applied Science University \\ E-mail: Khraim3@hotmail.com \\ Dr. Firas Muslam Al-Kaidah \\ Marketing Department, Middle East University, PO box 383, Amman 11610, Jordan \\ E-mail: falkaidah@meu.edu.jo \\ Dr. Daher AL-Qurashi \\ Marketing Department, Middle East University, PO box 383, Amman 11610, Jordan \\ E-mail: Dqurashi@meu.edu.jo
}

Received: May 18, 2011 Accepted: July 11, $2011 \quad$ Published: November 1, 2011

doi:10.5539/ijms.v3n4p105 URL: http://dx.doi.org/10.5539/ijms.v3n4p105

\begin{abstract}
The purpose of this paper is to provide an understanding of the influence of consumer religiosity on Jordanian consumer's evaluation of retail store attributes. Data collected in the survey have included retail stores attributes, religiosity and demographic characteristics of respondents. Data were collected from 800 random selected consumers in several shopping centres in Amman. Different methods of statistical analysis have been used such as mean differences, one way ANOVA, percentile, and factor analysis. The findings reveal that among the six factors considered (locational convenience, service, post purchase services, merchandise, kinship and local goods), the most important factor for consumers has been merchandise, which includes four items with cheaper prices scoring the highest mean among all items. Results of the hypothesis testing indicate that there was a difference between high, moderate and low consumers' religiosity in evaluating the importance of all retail store factors. This paper provides retailers with knowledge on consumer behaviour in Jordanian culture context by categorizing the attributes that are considered by consumers when making choices regarding where to shop.
\end{abstract}

Keywords: Consumers, Retail store attributes, Retailing, Religiosity, Islam, Jordan

\section{Introduction}

The study of consumer selection of retail store attributes can provide a wealth of information concerning how consumers choose a specific store. The Consumers' decision is associated with their perceptions of a store's ability to satisfy their needs and wants. Armed with this information, a retailer can then assess the relative strengths and weaknesses of their marketing programs with respect to their service offerings and make needed adjustments. In addition, investigations of a choice-attribute relationship can provide valuable assistance in identifying competitors and their relative strengths and weaknesses (Eroglu, et al., 1983; Gruca, 1989). The main issue for retailers is consumer choice; choice of product as well as choice from where to buy that particular product. In the process of evaluating retail store patronage, consumers consider a variety of factors, often referred to in retailing literature as store-choice evaluative criteria (Rosebloom, 1983). The importance of store attributes varies 
according to the type of product purchased, for example whether it is groceries, durables or services as well as the type of consumer, timing and the place. Differences in consumer choice and evaluation of store attributes can be attributed to many reasons such as, different culture, personality, and lifestyle. Previous studies in the area of culture and formation of consumption (e.g. Shaw \& Clarke, 1998) have generally identified cultural values as important factors in determining the consumption behavior of individuals. There is a considerable previous research which focused on the influence of culture various aspects of consumer behaviour. However, among this body of research, little attention was given to the influence of religion as an element of culture on consumer behaviour. The present study will address this issue, and so will enhance our knowledge on our local market by inclusion of new variables.

\section{Research Objectives}

The present study will examine the influence of Jordanian consumer religiosity on the selection of retail store attributes one of the fastest growing sectors. The main objectives of this study are:

- Exploring the importance of the retail store attributes and specifying which factors can be more significant in attracting more consumers.

- Studying the influence of different levels of religiosity on consumer selection of retail stores in Jordan.

\section{Literature Review}

Attributes are generally defined in marketing research textbooks as tangible and intangible characteristics of products that provide "subjective satisfactions" or "needs satisfaction to consumers". These attributes are used by applied marketing researchers in a number of ways, such as comparing and contrasting consumer images of competing stores and building models to explain customer satisfaction and services quality. Bruno and Giovanna (2005) suggest that attributes fall into three categories, each showing a different impact on customer satisfaction: (1) expected basic attributes can cause dissatisfaction if poorly or not delivered but do not lead to customer satisfaction if fully delivered. These dissatisfier attributes are minimum requirements; that is, those features that establish an entry "threshold" in the market. As they are prerequisites that customers take for granted, they are a necessary but not sufficient condition for satisfaction. (2) One-dimensional performance attributes cause satisfaction if fully delivered and dissatisfaction if poorly or not delivered. They are both a necessary and sufficient condition for satisfaction. (3) Unexpected exciting attributes cause satisfaction if fully delivered but do not lead to dissatisfaction if poorly or not delivered. These satisfier attributes are unexpected, but if properly delivered they generate delight. Hence, they are a sufficient but not necessary condition for satisfaction.

The root of identifying retail store attributes was indicated early in the traditional model by Fishbein (1966) who analyzed the relationship between belief, attitudes, and behavior. Fishbein applied his model to a retail situation. The model indicates that a consumer's attitude towards a retail store is a function of a) The degree of importance attached by the consumer to various attributes, and b) The consumer's perception of the degree to which a retail store possess each attribute. Decisions concerning store choice may be similar to process represented by traditional models of consumer decision making (e.g., Engel et al., 1993; Monroe \& Guiltinan, 1975). Monroe and Guiltinan model indicates consumer characteristics (demographics and lifestyle) that may affect the perceived relative importance of store attributes. Moreover consumers' attitudes toward stores and store choice may be influenced by the degree to which stores possess desired attributes.

Lindquist (1974-1975) summarized the literature conducted a meta-analysis on twenty-six studies designed to identify key attributes affecting store patronage behaviour. Lindquist found seven attributes that occur more frequently than others: (1) merchandise selection or assortment, (2) merchandise quality, (3) merchandise pricing, (4) locational convenience (5) merchandise styling or fashion, (6) general service, and (7) salesclerk service.

Tigert (1983) analyzed the results of thirty-eight studies across four retail sectors (retail food, fast food, do-it-yourself, and fashion). For retail food store-choice, Tigert performed a comparative analysis between the proportions of total numbers of attributes. He found that locational convenience is the most determinant attribute. Low price was the second strongest attribute. The sequence of importance of the attributes was as follows: (1) locational convenience, (2) low price, (3) merchandise assortment, (4) service, and (5) merchandise quality.

Lumpkin and Greenberg (1985) conducted a study on the importance of attributes for elderly consumers. The objectives of this study were to identify store attributes which elderly shoppers seek when buying apparel and to assess the relative importance of these attributes. The five most influential attributes are related to the quality/price relationship and finding satisfactory products. Consumers desired quality products and yet wanted attractive price-value for their money. They also want fashion goods of suitable style and size and the ability to return 
unsatisfactory goods. A second group of attributes of lesser but still significant determinants was identified. In addition to attractive everyday prices apparel consumers wants sales. They want advertised products to be available, easy to find and readable tags and labels are also desired. While convenient parking was desired, entrance to the premises, fast check out counters, close to other stores, close to home, phone order, and home delivery were not as important.

The influence of consumer religiosity on the importance of various retail department store attributes was investigated for the first time by McDaniel and Burnett (1990). The results showed that one aspect of religiosity, religious commitment, particularly measured by cognitive religiosity and one aspect of behavioural religiosity are significant in predicting the importance individuals place on certain retail evaluative criteria. Consumers with a high degree of cognitive religious commitment have viewed that sales personnel friendliness, shopping efficiency, and product quality as being of greater importance in selecting a retail store than did those low in cognitive religious commitment. Religious contribution, a behavioral component of religious commitment, was positively and significantly associated with sales personnel friendliness/assistance and credit availability.

Mokhlis (2009) examined the influence of religiosity on one aspect of consumer behaviour- shopping orientation. The research aimed to understand the relevancy of religiosity on consumer behaviour across different cultural settings, namely Islam, Buddhism, Hinduism and Christianity. The researcher used both religious affiliation and religious commitment to measure religiosity. The findings of Mokhlis revealed that the differences between consumer behaviours in general were much more overt for religiosity than merely for religious affiliation. This implies that religiosity may serve as a potentially powerful predictor and determinant of consumer behaviour.

Jessie et al., (2010) made a comparison between adolescents clothing motives in South Korean (SK) and United States (US) depending on their store selection criteria. They also examined whether adolescents with different primary clothing motives would have similar or different store selection criteria. Furthermore, Jessie et al., (2010) examined an interaction effect of country of residence and clothing motives on store selection criteria. Results showed that clothing motives and store selection criteria differed significantly between SK and US participants. Participants with different primary clothing motives had significantly different store selection criteria. Moreover, SK and US participants with the same primary clothing motive did not have significantly different store selection criteria.

\subsection{Retailing in Jordan}

The wholesale and retail trade sector has been one of the sectors that has benefited from the changes in the country's economic structure after Jordan entrant into the World Trade Organization (WTO) in April 2000. The retail sector in Jordan is consisted of small mixed retailers, small family business and bazaars. The introduction of supermarkets and superstores was a kind of re-shaping of the retail sector. Safeway Superstores, the first international supermarket to open in Jordan (U.S. franchise) have succeeded in making it possible for Jordanians to buy everything under one roof. This has prompted some local retailers to reinvent themselves. Shopping at supermarkets and superstores is becoming a leisure activity for the Jordanian consumers. Currently Jordan is witnessing a boom in supermarkets and superstores establishments. There has been a vertical and horizontal expansion of local and multinational superstores and supermarkets in Jordan. C-town a multinational superstore (U.S.) has four supermarkets and is adding two new outlets. While Carrefour (French) has opened two outlets in Amman in 2007, other supermarkets i.e. Abbadi supermarket, a local successful grocery store in Amman, now is expanding its superstore into 13000 sq. m. with a shopping area of $2600 \mathrm{~m} 2$. Al-Farid is in the process of expanding their present outlets and adding new outlets. An American style mall Al Mukhtar, expands its original business of gifts and home appliances, the first floor of $3000 \mathrm{sq}$. m. will be allocated for grocery supermarket.

The dependence of consumer in Amman on neighborhood stores has decreased, except for last minute food needs. Supermarkets are scattered in the suburbs of Amman and in other cities and villages of Jordan. Competition among retailers is continuously increasing and most consumers find this of benefit for them. In order to keep current customers and attract new ones, most supermarkets offer weekly specials, promotional discounts and integrated item offers to encourage consumers to purchase more. Home delivery service is very popular among the large retailers in Amman only. The objective of the delivery service is to create customer loyalty and is free of charge. Supermarkets located in malls or superstores run coffee shops, fast food restaurants and children playgrounds. Retailers are advertising about their products through roadside advertising posters, signs, newspapers, and weekly free advertising newspapers and on TV. Alcoholic beverages are limited to a few authorized supermarkets and dealers.

Despite this tremendous size and importance of retaling sector in Jordan, there is a little academic research on relating and identifying key retail store attributes in the consumer behaviour. Al-Tae'e 2002 studied the factors that 
influence the selection decision criteria of restaurants in Amman. He found that personal factors had the greatest effect on preference decision followed by demographics and behavioral factors. The study also showed that restaurant attributes such as internal décor and food type plays an important role in customer preference. Ibadat (1998) studied the shopping patterns of Jordanian families with high and moderate income. He found that there is a significant difference in shopping patterns of the two groups since high-income families patronize famous shopping malls while low-income families patronize supermarkets and grocery shops in the same residence area. This study did not show the reasons for preferring one shop over another.

Finally, the study of Al-dhumour and Al-Abbadi (2003) on attendance of the elderly market by elderly people in Jordan which was based on the lifestyle patterns using (AIO) showed that almost $49 \%$ of the sample goes shopping daily. The authors recommended using retail stores as the best method to reach those consumers and the main reason behind this was the convenience in reaching the retail stores. Finally, a study conducted by Abu Rumman (2003) focused on consumers' attitude towards Mega malls in Amman. The study tried to compare the differences in attitude between two well-known stores namely: Safe Way and C Town as well as the importance of location of each store. The study has found that price was the most important factor followed by location and quality.

\subsection{Religiosity}

Religiosity is a multidimensional concept containing numerous aspects such as beliefs, practice, experiences and consequential effects on daily life of an individual (O'Connell, 1978). Attempt to put measures of religiosity (or "religiousness," "religious commitment," "religious involvement," as variously called) has started early in the beginning of the present century. Because people can be religious in varying degrees, the most appropriate procedures for measuring religiosity are typically quantitative, yielding scores that can be correlated statistically with a range of other dimensions. The most comprehensive quantitative study on measuring religiosity was The Religious Factor, done by Lenski (1961). The study of Lenski shows that meaningful information on religious beliefs and practices can be obtained in quantitatively analyzable form. In addition, with the help of religion, the study has produced a descriptive social profile in terms of denomination, social class, age, race, and other conventional social classifications.

The recognition of the multidimensional nature of religiosity allows for a more thorough understanding of the potential importance of different dimensions of religiosity. Psychometric research conducted in the area of psychology has successfully produced a plethora of scales to measure a wide variety of religious phenomena including attitudes, beliefs and values (Hill \& Hood, 1999). Most research has focused upon indices of intrinsic (religion as an end), extrinsic (religion as a means) and quest (religion as a search) dimensions of religiosity. However, there is no consensus among experts as to the number of dimensions that make up the religiosity construct. Religiosity is an intricate concept and a variegated human phenomenon, and seems to cover considerable grounds such as behaviours, attitudes, beliefs, feelings and experiences. Religious scholars and sociologists do not agree on whether adequate measures of individual religiosity can be developed. Therefore such measures are subjectively devised by researchers to fit their research objectives. Thus, the content and number of religious dimensions vary considerably and may depend on the nature of the research, purpose and context.

\subsection{Operationalization of Islamic Religiosity}

Creating a new dimension, and especially in an area like religion, is not an easy task. This paper will use new construct for measuring Islamic religiosity in the context of Islamic countries created by khraim (2010). Jordan is unique because Islam is the official religion and the followers belong mostly to one ethnic group namely Arabs and other small ethnic groups which share the same religion and same culture. The Jordanians with their Islamic belief intermingle with other groups who adopt different religious beliefs. The dimensions introduced in this study are directed more toward practical behaviour. These dimensions are: Seeking religious knowledge, current Islamic issues, and sensitive products. The rationale behind selecting these dimensions is to encompass as many issues as possible so that the dimensions reflect the tenet that Islam is a complete way of life rather than a bundle of rituals in the narrow religious sense.

\subsubsection{Religious Knowledge}

This dimension is about how individuals try to increase their religious knowledge. The emphasis here is not on education per se. Many studies show that education contributes little to explain variations in religiosity. In this dimension we have tried to focus on different types of education which can really contribute to the religiosity of individuals, such as, attending religious talks at mosque, listening and watching religious programmes, reading religious books and so on. 


\subsubsection{Islamic Current Issue}

The third dimension is Islamic current issues. This concept of religion goes along with our view that religion is a complete way of life rather than a bundle of rituals in the narrow religious sense. According to this view, we have tried to include in this dimension current Islamic issues, which influence the behavior of individuals. This dimension contains 20 different aspects of daily life issues of Muslim individuals, such as the label of the food he buys, economy and currency speculation, implementation of Islamic law, apostate issue, preserving the Islamic manner in dressing, decline in the number of religious schools and prayers and so on. The purpose of this dimension is to measure the level of importance of such issues acording to the respondent.

\subsubsection{Sensitive Products}

The third dimension contains 13 statements related to the consumption of different products that may contain doubtful items. Some of these items may or may not contain prohibited ingredients. Highly religious individuals are expected to be very doubtful to use these products.

\section{Research Hypothesis}

The question arises as to whether Jordanian consumers with different levels of religiosity have different evalutions of retail store attributes. The research question posed in this paper is whether religiosity affects consumers' behaviour. Formally stated, the research question is:

H1. Jordanian consumers with different levels of religiosity exhibit differences in evaluating store attributes dealing with a) locational convenience, b) service, c) post purchase services, d) merchandise, e) kinship, and f) local halal food.

\section{Methodology}

In order to investigate the influence of religiosty on Jordanian consumers' evaluation of store attributes, data were collected through a self-administered questionnaire by random sampling in many shopping centre in Amman. A total of 800 usable questionnaires were obtained out of 1000 distributed. This is equivalent to 80.0 percent response rate. Part I contained respondents' demographics. Part II contained a list of store attributes. Part III consisted of 38 items measuring the three dimensions of religiosity. Reliability analysis was carried out to examine the internal consistency of the questionnire. For store attributes, Cronbach alpha was 0.86 , while the total Cronbach alpha for the three religiosity factors was 0.81 .

Questionnaire Design: The research instrument has contained three parts:

Part I: Examined the consumer's demographics. Demographic statements have included: gender, marital status, age, education, and income. Islam is the main religion in Jordan with a 5\% minority of Christians who all use Arabic language. Jordanians tend to have relatively large families and tend to be above the national average in having about 5.8 people in the household. Furthermore, Jordan's population tends to be relatively young with 19.3 years median age and characterized as the highest education level in the region with 89.1 percent educated.

Part II: Addresses the store attributes. A survey of literature has indicated that there are considerable variations among researchers in the number of relevant store attributes used in their studies dealing with determinants of store choice. For example, Lindquist (1974-75) came up with nine dimensions, and Kunkel and Berry (1968) used twelve attributes in their studies whereas, Lumpkin et al., (1985) used thirty-two store attributes while studying determinants of store choice. However, the literature on information processing capacity suggested that consumers would have trouble in evaluating too many attributes. In fact, Hansen (1969) reported that predictions of store patronage by using three attributes were as good as the ones that used 24 attributes. As a result of these findings, this study used only twenty-two store attributes that were generally identified by researchers as salient dimensions used by shoppers when formulating store choices. The focus of this part is to identify high influential store attributes, which Jordanian consumers stress in choosing their shopping centres. The influence of Twenty-two store attributes on patronage behaviour has been measured on a 5-point Likert-type scale as follows; $1=$ Not at all influential; 2 = Not influential, $3=$ Netural, $4=$ Influential, and $5=$ Very influential.

Part III: Addresses respondents' religiosity. Most of the research on measuring religisoity indicated that religiosity is multidimensional. The paper will utilize the three dimensions developed and tested on Jordanain consumers by (khraim, 2010) which include; Seeking religious knowldge, Islamic current issues, and senstive products as disscussd in section 3.3. The response format for seeking religious knowldge has been a 3-point rank scale $(1=$ Never, $2=$ Sometimes, $3=$ Most Frequent $)$. For Islamic current issues, the response format has been a 5 -point rank scale (ranging form $1=$ not important at all, to $5=$ the most important). While for sensitive products, the response format has been on a 3-point rank scale $(1=$ Do Not Hesitate, $2=$ Little Doubt, $3=$ Very Doubtful $)$. 


\subsection{Sample Characteristics}

In this section we will shed some light on the characteristics of the respondents with respect to their demographic profiles. The sample distribution for this study (Table 1) shows that male respondents are consisted of $346(43.2 \%)$ and $454(56.7 \%)$ females. Single respondents are consisted of 491(61.30\%), while the married category consisted of $292(36.6 \%)$. The divorced category has the smallest number of respondents with only $17(2.1 \%)$. The age profile shows that more than half of the respondents 412 (51.5\%) are ranged from 21-30 years, while $200(25.0 \%)$ are more than 31 years old.

\section{Analysis and Findings}

\subsection{Factor Analysis - Store Attributes}

Factor analysis has been used to find out the leading factors that can contribute to understanding the consumer evaluation of store attributes as well as to summarize the information to a smaller set of variables. Twenty-three retail store attributes go into factor analysis and overall, nineteen retail store attribute loaded significantly (a factor loading of at least 0.50 ) on one of the factors as shown in Table 2. After applying the reliability test for the factors, it was decided to use the first six factors and ignore the last factor, due to low reliability which is equal to 0.45 . The cumulative percentage of the variance for the six factors is $60.5 \%$ which was described by Hair et al., $(1999$, p.104) as satisfactory. The factors were subjected to varimax rotation to provide a simple column structure for interpretation. Based on the factor loadings in each pattern, the factor patterns were characterized as locational convenience, service, return item policy, merchandise, kinship and local halal goods.

\subsection{Interpretation of Factors}

Factor 1 (locational convenience): The first factor store locational convenience is related to physically going to a particular store for the purpose of shopping. Stores that are located near a bus interchange or mass rapid transit station are likely to enjoy more exposure and draw greater traffic volume than stores that are not easily accessible. This factor includes five related attributes: the consumer convenience of a particular store relative to the other stores, the closeness of store to house and work place, the road/traffic is not congested, and easy parking.

Factor 2 (Service): The second factor includes service and physical oriented attributes of the store. The presence of service can reduce the non-monetary sacrifices made by shoppers (e.g., time) and also increase the benefits of shopping (e.g. convenience through facility design etc.). The service attribute includes the extent to which the sales personnel satisfy the social needs of consumers through courtesy and good service. Courteous staff will strengthen the store-consumer relationship and encourage repeated visits and favorable word-of-mouth transmission by consumers to their friends. The physical characteristics of the store pertain to the arrangement of goods and to the extent of interior set-up attractiveness. A well-planned layout not only brings about a coordinated visual display of a range of merchandise, but also guides the flow of customer traffic to all parts of the store, and is more likely to secure a favorable consumer perception. Good service such as delivery of merchandise to customers' homes, and installation is also important for consumers.

Factor 3 (Post Purchase Services): The third factor pertains to the store policy with regard to post purchase services. The shopping experience does not necessarily end when a sales transaction has been concluded and the customers physically leave the premises. Store willingness to accept the wrongly bought items and to return non-quality products is welcomed by customers. Consumers may equate this attribute with an absence of hassles and having to talk with or write letters to various store personnel in order to get the matter resolved fairly.

Factor 4 (Merchandise): The fourth factor includes merchandise selection and product availability in the store. This factor expresses concerns of the customer with regard to product varieties (i.e., whether the store has a wide selection of merchandise). This factor also includes cheaper prices (whether the merchandise offered by the store is a good value for money), frequent sales offer, and controlled items are well stocked inside the store.

Factor 5 (Kinship): The fifth factor deals with those who owns and works in the store. This factor deals with whether the owner is the consumers relative or if his/her relative is working in the store. This factor makes consumer sure about the types of goods such as halal, a good source of information on sales, and expectancy of flexible policy to return goods.

Factor 6 (Local Goods): The last factor pertains to the availability of local products. This factor deals with whether the store is selling local goods and not selling alcoholic beverages. This factor enables consumers to buy local goods due to their ability to distinguish the local halal goods guaranteed by local authorized bodies. 


\subsection{Descriptive Analysis of Store Attributes by Factors}

To achieve the first objective of this study, this section will provide a descriptive analysis for different store attributes by factors that highlight and understand the nature and importance of each attribute in detail. Table 3 presents the distribution, percentage and mean of responses related to store attributes.

The first factor of attributes is related to Locational convenience. Five items have been identified that fit into this classification. The highest mean rating in this factor is item I - (Easy parking) and received a mean rating of 4.22. The distribution of response shows that $87.7 \%$ of the respondents have rated the importance of this item as agree and strongly agree. The second highest item is $\mathrm{h}$ - (The road/traffic is not congested) and have received a mean rating of 4.04. The distribution of responses shows that 80.5 percent of the respondents have rated the importance of these items as agree and strongly agree, while in the third position, item e- (Near my house), have received a mean rating of $3.72 \%$. About 66.2 percent of the respondents have rated the importance of these items as agree and strongly agree. Item g- (Near to other Shops) has ranked fourth and has received a mean rating of $3.68 \%$. The distribution of the responses shows that 65.2 percent of the respondents have rated the importance of these items as agree and strongly agree. While items f- (Near to my working place) has ranked fifth with a mean rating of 3.55. Only 61.7 percent rated the importance of this item as agree and strongly agree respectively. From this descriptive statistics it is clear that I- (Easy parking) has received the highest mean rating in this group, which means that the consumers place high importance on easy parking.

The second factor of attributes is related to Service. This group consists of four items. Item d- (Good services) has received the highest mean in this group with 4.42. The distribution of response shows that 94.5 percent of respondents have rated the importance of this item as agree and strongly agree. Item c- (Courteous staff) has received the second highest mean in this group with a rating of 4.40 , with 92.4 of respondents rating the importance of this item as agree and strongly agree. Item $b$ - (The goods are nicely arranged) has received a mean rating of 4.00 and has ranked third in this group. About $85.3 \%$ rated the importance of this item as agree and strongly agree. The last item in this group is a- (Attractive interior set-up) and received a mean rating of 3.88. Approximately 75.7 percent of the respondents have rated the importance of this item as agree and strongly agree. The descriptive statistics of the second factor shows that good service is the key factor to attract consumers. This means that improving the services provided by the store and staff courtesy can be very influential factors that will draw consumer attention and enhance the image of the store and consequently increase sales volumes.

The third factor is related to store Post purchase services. This group consists of two items. Item t- (Willing to accept to return non-quality product) has received a mean rating of $4.35 \%$. The distribution of responses shows that 82.5 percent of respondents have rated the importance of this item as agree and strongly agree. While item u(Willing to accept to return wrongly bought product) has received slightly lower mean rating of $4.26 \%$. The distribution of responses shows that 80.7 percent of respondents have rated the importance of this item as agree and strongly agree. In general, the descriptive statistics of the two items indicates that consumers place a high importance on post purchase services. This means that the more flexible the store is in terms of its return items policy the more the store will gain an advantageous place over other competitors.

The fourth factor pertains to Merchandise which consists of four items. Item s- (cheaper price) has received the highest mean rating among all items with 4.539. The distribution of responses shows that 93.7 percent of the respondents rated the importance of this item as agree and strongly agree. Item k- (Product varieties) has ranked second in this factor and received a mean rating of 4.41. Approximately 92.0 percent of the respondents have rated the importance of this item as agree and strongly agree. While items o- (Frequent sales offer) ranked third with a 4.20 mean. About 83.2 percent of the respondents rated the importance of this item as agree and strongly agree. Item $\mathrm{p}$ - (Controlled item are well stocked) received a mean rating of 4.14. The distribution of responses shows that 82.9 of the respondents have rated the importance of this items as agree and strongly agree. The descriptive statistics for this item shows that cheaper prices attract consumers more than any other product attribute. Managers must be very careful in drawing out their pricing strategies, hence it's successfully implemented, and the value for price scheme will increase the store potential of attracting more shoppers.

The fifth factor consists of two items related to kinship. The mean rating of statement v- (The owner is my acquaintance) is 3.67 and 63.5 percent of responses has rated the importance of this item as agree and strongly agree. For the second statement w- (My relatives are working there) the mean rating is 3.31. The distribution of responses shows that 44.0 percent has rated the importance of this item as agree and strongly agree. This means that retailers must work harder on creating more effective customer relationship programes.

The sixth factor of store attributes contains two items of local products. The first item n- (Alcoholic beverages not sold in the mall) has received the highest mean rating of 4.52. The distribution of respondent shows that 93.2 
percent of the respondents have rated the importance of this item as agrees and strongly agrees. This can indicate the revival of religion awareness among consumers. While the second item $\mathrm{m}$ - (selling local goods) has received mean rating 3.65. The distribution of the responses for the importance of this item as agree and strongly agree was 65.0 percent.

\subsection{Hypothesis Testing}

As we noticed in the previous sections, the scales used to measure the items of religiosity variable are different. These differences can be corrected by appropriately transforming the data. One of the most common scale transformation procedures is standardization. Standardization allows the researcher to compare variables that have been measured using different types of scales (Aaker, 1998, p.444). This can be achieved by forcing the variables, by standardization, to have a mean equal to zero and the standard deviation equal to one. The transformation is based on the proportional property of the normal distribution:

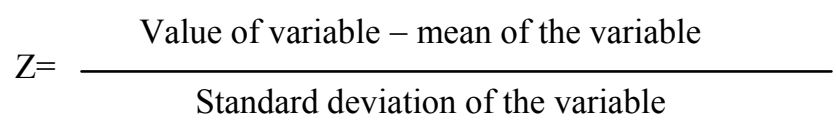

As mentioned earlier, three dimensions can be used to index the religiosity, namely sensitive products, current issues and religious education. All the items of the three dimensions have been standardized, summed up and averaged to obtain an overall measure, which we refer to as consumer religiosity. This composite measure of religiosity has been then used to categorize respondents into three groups by the percentile technique. Percentile is usually used to identify the status/position of specific object within the general frame of the objects.

A One way ANOVA test has been used to see if there was are any significant difference in the evaluation of retail store attributes among the three levels of religiosity. Table 4 indicates that there is a significant variation in the mean of in store attributes among the three levels of religiosity. The merchandise seemed to be the most important with the highest mean among all attributes. All the items differ among the three levels of religiosity except one item, which is service. Summaries of hypothesis testing are presented in exhibit 1.

\section{Conclusions}

The result of this study provides an insight into understanding Jordanian consumers' evaluation and selection of retail store attributes. The findings indicate that evaluation of retail store attributes is influenced by consumer's religiosity. In general consumer religiosity is an important indicator of retail store attributes selection. Among the six factors were considered, the most important factor for consumers has been merchandise, (which includes of four items) with cheaper prices scoring the highest mean among all items. Results of the hypothesis testing indicates that there was a difference between high, moderate and low consumers' religiosity in evaluating the importance for all retail store factors except for the service factor, where there was no difference between high and moderate levels, however there was a difference between them and low level.

Based on the above results, Jordanains' with different levels of religiosity tend to evaluate retail store attributes differently. This can lead to many implications to marketing, retail and promotion managers. The factor of locational convenience is an important attribute since highly religious people are so aware of performing their religious duties and especially praying five times a day on exact time. Store location is also very important if religiosity is a factor in determining the most likely traffic patterns to and from places of worship or to and from places where certain religious preferences groups predominate at certain large employers or recreational pursuits. A previous knowledge on the religious census of specific market area, and comparing sales of religious geographical concentration with other locations, may bring new definition to efforts to reach the target profile group for whom the store is created.

The second significant store attribute is service. Religious individuals tend to be more dependent and sociable. In this case managers must emphasize attaching a higher level of importance to friendliness, courtesy, and assistance provided by retail sales personnel. A salespersons behavior and performance are important cue in influencing buyer decision- making, trust-based relationships and overall customer satisfaction. It is important for managers to assess the behavioral orientation, motivations and cognitive attributes of potential salespeople along with their ability and willingness to understand and flex to various buyer situations and expectations during the recruiting process.

The return item policy has been also found to be influenced by religiosity. Since trust is a religious character, managers must create and improve a good store image, which links the store with fair dealing, by showing store acceptance to return wrong and non-quality products. Doing so, will enhance the reliability and consequently will 
promote the store image. The fourth significant relationship is between religiosity and merchandise. Since products with an Islamic label are important to Muslim consumers, managers can improve their product mix by increasing product variety with the Halal label. They can also relate the selling of these products to charitable acts to attract more consumers. Moreover, they can announce sales offer on special religious day such as Fridays or special religious occasions such as during the holy month of Rammdan or other religious festivals.

The fifth significant relationship is between religiosity and kinship. Consumers can be skeptical about those product sold by unknown salesmen. To eliminate this doubt, store managers need to improve the relationship between management programmes and their customers. The last significant relationship is between religiosity and local halal goods. The emphasis on the availability of local food and non-alcoholic items and beverages is an important and unique feature for retail stores. This is also a good opportunity for production managers to enhance their production of Islamic products such as soft drinks, ice cream, fast food and fruit juice, since Muslim consumers will prefer those products produced by Muslims.

Findings from this research on store attributes and religiosity show that availability of a range of products is not the only reason to attract consumers to that particular store. The analysis shows that many factors are also important for consumers with different levels of religiosity such as convenience, price, merchandise, and return item policy.

For future research it's strongly recommended to study the influence of religiosity on other marketing and consumer issues. For example, how religiosity can affect consumer decision making process concerning product, services, and places.

\section{References}

Abu Rumman, A. (2003). Evaluation of Jordanian consumer attitude towards Departmental stores. Jordan Journal of Applied Science, 6 (1), 69-95.

Al-dhumour, H., and Al-Abbadi, H. (2003). Classifying the Market for Elderly People in Jordan According to Their Life Style Patterns. Dirasat for Management Science, 30 (1), 23-39.

Al-Tae'e, H. (2002). Factors Influencing Food Preference Decision of Restaurant Clients. Dirasat for Management Science, 29(2).

Bruno, B., and Giovanna, P. (2005). Understanding the relationship between attribute performance and overall satisfaction: Theory, measurement and implications. Marketing Intelligence \& Planning, 23(6), 543-561. http://dx.doi.org/10.1108/02634500510624110

Engel, James .f, Roger, d. Blackwell and Paul, M. Miniard (1995). Consumer Behavior. (8th edition). Dryden Press, Harcourt Brace College publishing, p95.

Eroglu, S. A., Omura, G. S., and Machleit, K. A. (1983). Evoked set size and temporal proximity to purchase. In Murphy, P. et al. (Eds.), Proceedings of AMA Educators' Conference, Series No. 3. American Marketing Association, Chicago, IL, 97-101.

Eugene, J. (1997). An Analysis of consumer food shopping behavior using supermarket scanner data: Differences by income and location. American journal of Agriculture Economics, 5, 1437-1443.

Fishbein, M. (1966). The Relationship between Belief, Attitudes, and Behavior. Cognitive Consistency. (Shel, Feldman, Ed.). New York, 199-223.

Fishbein, M., and Ajzen, I. (1974). Attitude towards Objects as Predictors of Single and Multiple Behavioral Criteria. Psychological Review, 81, 59-74. http://dx.doi.org/10.1037/h0035872

Gruca, T. S. (1989). Determinants of choice set size: an alternative method for measuring evoked sets". In Srull, T. K. (Ed.) Advances in Consumer Research, Vol. 17. Association for Consumer Research, Ann Arbor, MI, 515-21.

Hair, J.F., Anderson, R.E., Tatham, R.L., and Black, W.C. (1995). Multivariate Data Analysis. Simon and Schuster, New York.

Hansen, Robert A., and Terry, D. (1977-8). An Empirical Investigation of Attribute Importance in Retail Store Selection. Journal of Retailing, 53 (4), 54-72.

Hill, P. C., \& Hood, R. W. (1999). Measures of religiosity. Birmingham, AL: Religious Education Press.

Jessie H., Chen-Yu., Keum-Hee, H., \& Yoo-Kyoung Seock. (2010). Adolescents' clothing motives and store selection criteria: A comparison between South Korea and the United States. Journal of Fashion Marketing and Management, Vol. 14, No.1, pp.127 - 144. http://dx.doi.org/10.1108/13612021011025465

Khraim, Hamza (2010). Meauring religiosity in consumer research from Islamic perspective. International 
Journal of marketing Studies, 2 (2), November.

Lenski, G. (1961). The Religious Factor. New York: Doubleday \& Company.

Lindquist, Jay D., (1974-75). Meaning of Image. Journal of Retailing, 50 (Winter), 29-38.

Lumpkin, James R., and Greenberg, Barnett A. (1985). Marketplace Needs of the Elderly: Determinant Attributes and store choice. Journal of Retailing, 61(2), 75-105.

McDaniel, S. W., \& Burnett, J. J. (1990). Consumer religiosity and retail store evaluative criteria. Journal of the Academy of Marketing Science, 18, 101-112. http://dx.doi.org/10.1007/BF02726426

Mokhlis, S. (2009). Relevancy and Measurement of Religiosity in Consumer Behavior Research. International Business Research, 2 (2), 75-84.

Monroe, K. B., \& Guiltinan, J. P. (1975). A path-analytic exploration of retail patronage influences. Journal of Consumer Research, 2, 19-28. http://dx.doi.org/10.1086/208612

Nicosia, F. M., \& Mayer, R. N. (1976). Toward a sociology of consumption. Journal of Consumer Research, 3 , 65-75. http://dx.doi.org/10.1086/208653

O'Connell, B. (1978). Dimensions of religiosity among Catholics. Review of Religious Research, 16 (3), 198-207. http://dx.doi.org/10.2307/3510357

Qatmeen Riyad. (2003). Al Rai Daily News Paper, March, 27, Issue 11880.

Rosenbloom, B. (1983). Store Image Development and the question of congruency. In Darden, W.R. and Luusch, R.F. (Eds). Patronage Behavior and Retail Management. Amsterdam: Elsevier Science, 141-149.

Schiffman, Leon, G., and Kanuk, Lealie, Lazar (1997). Consumer Behavior. (Sixth edition). Prentice Hall, 446.

Shaw, D. S., \& Clarke, I. (1998). Culture, consumption and choice: Towards a conceptual relationship. Journal of Consumer Studies and Home Economics, 22 (3), 163-168. http://dx.doi.org/10.1111/j.1470-6431.1998.tb00727.x

Sheth, Jagdish N. (1983). An Integrative Theory of Patronage Preference and Behavior. In William R. Darden and Robert F. Lusch Eds. Patronage Behavior and retail management. New York: North-Holland, 9-28.

Tigert, Douglus J. (1983). Pushing the hot Buttons for a Successful retailing strategy. In patronage behavior and retail management. Prentice Hall, 251-291. 
Table 1. Profile of demographic characteristics of the total sample

\begin{tabular}{|l|c|c|c|}
\hline Demographic & Male & Female & Total \\
\hline Gender & $346(43.2 \%)$ & $454(56.7 \%)$ & $800(100 \%)$ \\
\hline Marital Status: & & & \\
Single & $214(26.7 \%)$ & $277(34.6 \%)$ & $491(61.3 \%)$ \\
Married & $121(15.1 \%)$ & $171(21.3 \%)$ & $292(36.6 \%)$ \\
Divorced & $11(1.37 \%)$ & $6(0.75 \%)$ & $17(2.12 \%)$ \\
\hline Age (Years): & & & \\
$<20$ & $34(4.2 \%)$ & $25(3.1 \%)$ & $59(7.3 \%)$ \\
$21-30$ & $199(24.8 \%)$ & $213(26.6 \%)$ & $412(51.5 \%)$ \\
$31-40$ & $112(14.0 \%)$ & $88(11.0 \%)$ & $200(25.0 \%)$ \\
$>40$ & $68(8.5 \%)$ & $61(7.6 \%)$ & $129(16.1 \%)$ \\
\hline Education: & & & \\
Diploma & $77(9.62 \%)$ & $58(7.25 \%)$ & $135(16.8 \%)$ \\
First Degree & $245(30.6 \%)$ & $257(32.1 \%)$ & $502(62.7 \%)$ \\
Postgraduate & $69(8.6 \%)$ & $94(11.7 \%)$ & $163(20.3 \%)$ \\
\hline Income & $63(7.8 \%)$ & $34(4.20 \%)$ & $97(12.0 \%)$ \\
High & $246(30.7 \%)$ & $289(36.1 \%)$ & $535(66.8 \%)$ \\
Middle & $45(5.6 \%)$ & $123(15.3 \%)$ & $168(20.9 \%)$ \\
Low & & & \\
\hline Number of Children: & $157(19.6 \%)$ & $284(35.5 \%)$ & $441(55.1 \%)$ \\
No Children & $144(18.0 \%)$ & $129(16.1 \%)$ & $273(34.1 \%)$ \\
Less than 5 & $56(16.5 \%)$ & $30(9.1 \%)$ & $86(10.7 \%)$ \\
5 and More & &
\end{tabular}

Table 2. Summary of structure of factors of retail store attributes

\begin{tabular}{|l|c|c|c|}
\hline Factor Composition & Factor Loadings & $\begin{array}{c}\text { Eigen } \\
\text { Value }\end{array}$ & $\begin{array}{c}\text { \% of variance } \\
\text { explained }\end{array}$ \\
\hline Factor 1 (locational convenience) & 0.821 & & \\
f) Near to my working place & 0.781 & & \\
h) The road/traffic is not congested & 0.718 & 5.886 & 26.656 \\
i) Easy parking & 0.699 & & \\
e) Near to my house & 0.600 & & \\
g) Near to other shops & 0.811 & & \\
\hline Factor 2 (Service) & 0.802 & 2.211 & \\
a) Attractive interior set-up & 0.771 & & \\
d) Good services & 0.578 & \\
c) Courteous staff & & & \\
b) The goods are nicely arranged & 0.836 & 1.763 & 7.960 \\
\hline Factor 3 (Post Purchase services) & 0.844 & & \\
u) Willing to accept the wrongly bought item & & & \\
t) Willing to accept returned non-quality product & 0.835 & & \\
\hline Factor 4 (Merchandise) & 0.732 & 1.674 & \\
s) Price is Cheaper & 0.716 & & \\
o) Frequent sales offer & 0.555 & & \\
k) Product varieties & & & \\
p) Controlled items are well stocked & 0.714 & 1.167 & \\
\hline Factor 5 (kinship) & 0.784 & & \\
v) The owner is my relative & & & \\
w) My relatives are working there & 0.586 & 1.424 & \\
\hline Factor 6 (Local Goods) & & & \\
m) Selling local goods & & \\
n) Alcoholic beverages not sold in the mall & & \\
\hline
\end{tabular}


Table 3. Distribution, percentage and mean of responses related to store attributes

\begin{tabular}{|l|c|c|c|c|c|c|c|}
\hline & & \multicolumn{7}{|c|}{ Scale and Percentage } & \\
\hline Statement & $\mathrm{N}$ & $\begin{array}{c}1 \\
(\%)\end{array}$ & $\begin{array}{c}2 \\
(\%)\end{array}$ & $\begin{array}{c}3 \\
(\%)\end{array}$ & $\begin{array}{c}4 \\
(\%)\end{array}$ & $\begin{array}{c}5 \\
(\%)\end{array}$ & Mean \\
\hline i) Easy parking & & $(1.1$ & 2.1 & 9.1 & 47.8 & 39.9 & 4.22 \\
h) The road/traffic is not congested & 798 & 1.4 & 6.0 & 12.2 & 46.0 & 34.5 & 4.04 \\
e) Near my house & 800 & 1.9 & 13.6 & 18.6 & 43.4 & 22.8 & 3.72 \\
g) Near to other shops & 800 & 1.0 & 7.7 & 26.1 & 43.3 & 21.9 & 3.68 \\
f) Near to my working place & 795 & 1.2 & 6.8 & 30.3 & 39.9 & 21.8 & 3.55 \\
\hline d) Good services & 800 & 1.6 & 1.1 & 2.8 & 45.3 & 49.2 & 4.42 \\
c) Courteous staff & 800 & 1.2 & 1.4 & 5.0 & 47.3 & 45.1 & 4.40 \\
b) The goods are nicely arranged & 800 & 1.0 & 2.2 & 11.5 & 56.6 & 28.7 & 4.00 \\
a) Attractive interior set-up & 793 & 1.9 & 6.5 & 15.9 & 45.8 & 29.9 & 3.88 \\
\hline t) Willing to accept to return non-quality product & 800 & 0.4 & 6.0 & 11.1 & 30.1 & 52.4 & 4.35 \\
u) Willing toaccept to return wrongly bought product & 798 & 1.3 & 4.1 & 14.1 & 40.7 & 40.0 & 4.27 \\
\hline s) Price is cheaper & 798 & 1.7 & 1.5 & 2.9 & 34.2 & 59.5 & 4.53 \\
k) Product varieties & 798 & 1.8 & 1.7 & 4.5 & 41.0 & 51.0 & 4.41 \\
o) Frequent sales offer & 800 & .0 & 4.0 & 12.8 & 41.3 & 41.9 & 4.20 \\
p) Controlled items are well stocked & 799 & 1.0 & 4.2 & 11.9 & 43.2 & 39.7 & 4.17 \\
\hline v) The owner is my acquaintance & 800 & 1.1 & 11.2 & 24.2 & 38.0 & 25.5 & 3.67 \\
w) My relatives are working there & 800 & 5.5 & 15.3 & 35.2 & 25.5 & 18.5 & 3.31 \\
\hline n) Alcoholic beverages not sold in the mall & 798 & .9 & 1.0 & 5.8 & 34.6 & 58.6 & 4.52 \\
m) Selling local goods & 797 & 1.1 & 8.3 & 25.6 & 48.1 & 16.9 & 3.66 \\
\hline
\end{tabular}

Table 4. The results of one-way anova with religiosity and store attributes

\begin{tabular}{|l|c|c|c|c|c|c|}
\hline \multicolumn{7}{|c|}{ ONE-WAY ANOVA RESULTS } \\
\hline Store Attributes & Low & Mode-rate & High & F-value & P-value & $\begin{array}{c}\text { Sign Group } \\
\text { Difference }\end{array}$ \\
\hline Location & 3.68 & 3.90 & 4.23 & 19.5 & .000 & H vs. M vs. L \\
\hline Service & 3.94 & 4.18 & 4.33 & 12.2 & .000 & H, vs.M vs. L \\
\hline Post purchase services & 3.76 & 4.01 & 4.42 & 26.1 & .000 & H vs. M vs. L \\
\hline Merchandise & 3.94 & 4.16 & 4.48 & 32.6 & .000 & H vs. M vs. L \\
\hline Kinship & 3.38 & 3.65 & 3.96 & 16.6 & .000 & H vs. M vs. L \\
\hline Local halal food & 3.22 & 3.57 & 4.01 & 52.0 & .000 & H vs. M vs. L \\
\hline
\end{tabular}

Table 5. Hypotheses testing: store attributes across the three levels of religiosity

\begin{tabular}{|l|c|}
\hline $\begin{array}{l}\text { Jordanian consumers exhibiting different levels of religiosity are expected to differ in their } \\
\text { store attributes selection dealing with Location. }\end{array}$ & Significant \\
\hline $\begin{array}{l}\text { Jordanain consumers exhibiting different levels of religiosity are expected to differ in their } \\
\text { store attributes selection dealing with Service. }\end{array}$ & Significant \\
\hline $\begin{array}{l}\text { Jordanain consumers exhibiting different levels of religiosity are expected to differ in their } \\
\text { store attributes selection dealing with post purchase services }\end{array}$ & Significant \\
\hline $\begin{array}{l}\text { Jordanain consumers exhibiting different levels of religiosity are expected to differ in their } \\
\text { store attributes selection dealing with merchandise. }\end{array}$ & Significant \\
\hline $\begin{array}{l}\text { Jordanain consumers exhibiting different levels of religiosity are expected to differ in their } \\
\text { store attributes selection dealing with kinship. }\end{array}$ & Significant \\
\hline $\begin{array}{l}\text { Jordanain consumers exhibiting different levels of religiosity are expected to differ in their } \\
\text { store attributes selection dealing with local goods. }\end{array}$ & Significant \\
\hline
\end{tabular}

